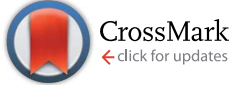

Cite this: RSC Adv., 2016, 6, 5491

Received 20th October 2015

Accepted 31st December 2015

DOI: $10.1039 / \mathrm{c} 5 \mathrm{ra} 21969 \mathrm{~h}$

www.rsc.org/advances

\section{Base free synthesis of iron oxide supported on boron nitride for the construction of highly functionalized pyrans and spirooxindoles $\uparrow$}

\author{
Aniruddha Molla and Sahid Hussain* \\ Boron nitride supported iron oxide $\left(\mathrm{BN}_{\mathrm{aFe}} \mathrm{O}_{4}\right)$ network was achieved via chemical reduction followed by \\ aerial oxidation in absence of base. The prepared $\mathrm{BNaFe}_{3} \mathrm{O}_{4}$ was characterized by powder XRD, FT-IR, \\ Raman, BET and FE-SEM. The catalytic property was subsequently investigated for one-pot multicomponent \\ domino reaction for the synthesis of highly functionalized pyrans and spirooxindoles derivatives on water. \\ The present method is simple, high yielding, recyclable and requires no column chromatography.
}

\section{Introduction}

Heterogeneous catalysis has been known for many years and become expediently essential for efficient organic transformations over the past few years. ${ }^{\mathbf{1 , 2}}$ 'Nanocatalysis' is an important growing field in catalysis science because of its small size and high surface area and thereby reducing the amount of catalyst and cost., ${ }^{3,4}$ Due to the difficulties in separation of nanocatalyst, chemists started to use solid-supports to make it heterogeneous. Solid-supported catalysts are vital and mounting field in semi-heterogeneous catalysis ${ }^{5}$ where surface functionalization of non-magnetic nanoparticles with ligands provides a well-designed way to bridge the gap between heterogeneous and homogeneous catalysis. ${ }^{6}$

Boron nitride (BN), consists of equal numbers of boron and nitrogen atoms, is isoelectronic with carbon in cubic and hexagonal forms and is analogous to graphite. The strong $\mathrm{B}-\mathrm{N}$ covalent bonds within hexagonal boron nitride (h-BN) impart high mechanical, thermal and chemical stability. In view of the above, $\mathrm{BN}$ has earned notice in the field of heterogeneous catalysis over the past decade..$^{7-9}$ One of the important interesting features of BN is that it behaves as both Lewis acid and Lewis base. ${ }^{10}$ To enhance ease of separation and Lewis basicity, we thought to incorporate iron oxide on $\mathrm{BN}$. In the last few years, different forms of iron oxides [such as $\mathrm{FeO}$ (wustite), $\mathrm{Fe}_{2} \mathrm{O}_{3}$ (iron III oxides), $\alpha-\mathrm{Fe}_{2} \mathrm{O}_{3}$ (hematite), $\beta-\mathrm{Fe}_{2} \mathrm{O}_{3}$ (beta phase), and $\gamma-\mathrm{Fe}_{2} \mathrm{O}_{3}$ (maghemite)] were extensively used as a powerful catalyst for many organic transformations due to its special features like less toxic, stable, inexpensive, and recyclable. ${ }^{11-15} \mathrm{~A}$ wide variety of methods have been reported in the literature for the synthesis of $\mathrm{Fe}_{3} \mathrm{O}_{4}$ nanoparticles such as hydrothermal process, ${ }^{16}$ sonochemical method, ${ }^{17}$ micro-

Department of Chemistry, Indian Institute of Technology Patna, Patna 800 013, India. E-mail: sahid@iitp.ac.in; Fax:+91-612-227-7383; Tel: +91-612-255-2022

$\dagger$ Electronic supplementary information (ESI) available: Spectral data of all compounds are available. See DOI: $10.1039 / \mathrm{c} 5 \mathrm{ra} 21969 \mathrm{~h}$ emulsion technique, ${ }^{18}$ electrochemical route, ${ }^{19}$ co-precipitation ${ }^{20}$ and microwave method. ${ }^{21-23}$ In order to synthesize iron oxide on $\mathrm{BN}$, we follow a new technique which involves reduction of $\mathrm{Fe}^{2+}$ to $\mathrm{Fe}^{0}$ followed by aerial oxidation to $\mathrm{Fe}_{3} \mathrm{O}_{4}$ and then applied to multicomponent reactions.

Multicomponent reactions (MCRs) of more than two substrates offer the maximum potential for molecular diversity in one step and atom economic way, with lowest synthetic time and effort. ${ }^{24,25}$ Knoevenagel condensation in combination with Michael addition has been dynamically used for synthesis of highly functionalized pyrans and spirooxindoles derivatives in domino fashion due to its wide medicinal and pharmaceutical application such as anticancer, ${ }^{26}$ anti-HIV ${ }^{27}$ antimalarial, ${ }^{28}$ antitubercular ${ }^{29}$ etc. Fig. 1 represents some bioactive pyran derivatives. ${ }^{30-32}$ In continuation of our ongoing research on the synthesis of highly functionalized pyran and spirooxindole derivatives ${ }^{33,34}$ in domino fashion, we used boron nitride supported iron oxide, $\mathrm{BN} @ \mathrm{Fe}_{3} \mathrm{O}_{4}$ as an effective, reusable and proficient catalyst for the transformations.

\section{Materials and methods}

Ferrous sulphate heptahydrate $\left[\mathrm{FeSO}_{4} \cdot 7 \mathrm{H}_{2} \mathrm{O}\right]$, hexagonal boron nitride [h-BN] with particle size $\sim 1 \mu \mathrm{m}$, sodium borohydride $\left[\mathrm{NaBH}_{4}\right]$, citric acid, and ethanol (EtOH) were all analytical

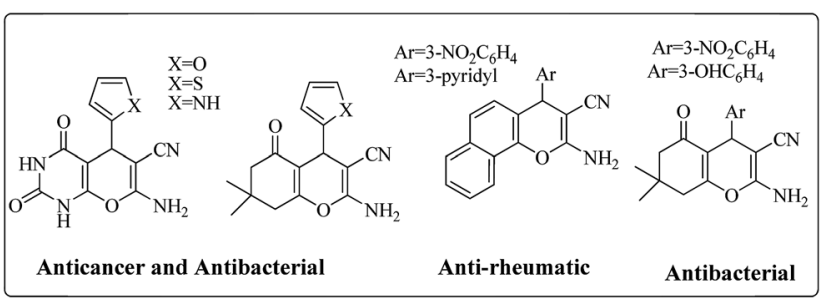

Fig. 1 Pharmacologically active synthetic 2-amino-3-cyano-4Hpyran derivatives. 
grade and used without further purifications. Double distilled water was employed throughout the experiments.

\section{Preparation of $\mathrm{BN} @ \mathrm{Fe}_{3} \mathrm{O}_{4}$}

$\mathrm{BN} @ \mathrm{Fe}_{3} \mathrm{O}_{4}$ was prepared through simple one-pot synthetic method, using citric acid as stabilizing agent. In typical experiment, $100 \mathrm{ml}$ water was added in round bottom flask containing ferrous sulphate hepta-hydrate $\left[\mathrm{FeSO}_{4} \cdot 7 \mathrm{H}_{2} \mathrm{O}\right](2500 \mathrm{mg}$, $9 \mathrm{mmol}$ ), boron nitride (2000 $\mathrm{mg}, 81 \mathrm{mmol}$ ) and citric acid (165 $\mathrm{mg}, 0.75 \mathrm{mmol}$ ) and mixture was vigorously stirred for $10 \mathrm{~min}$. Then sodium borohydride $\left[\mathrm{NaBH}_{4}\right](600 \mathrm{mg}, 15 \mathrm{mmol})$ was added in slots to the stirring solution and was continued for 10 min. The reaction mixture was allowed to settle down and then was filtered and washed with ethanol and water for at least three times. The residue was kept overnight in open air and was finally collected after dried under vacuum. The formation $\mathrm{BN} @ \mathrm{Fe}_{3} \mathrm{O}_{4}$ is pictorially represented in Scheme 1. $\mathrm{Fe}_{3} \mathrm{O}_{4} \mathrm{NPS}$ was prepared by hydrothermal synthesis as reported earlier. ${ }^{20}$

\section{Characterizations methods of catalyst}

Fourier transform infrared (FT-IR) spectra were recorded in $\mathrm{KBr}$ on a Shimadzu IR Affinity I. Powder X-ray diffraction (PXRD) study was carried out on a Rigaku X-ray diffractometer at a voltage of $35 \mathrm{kV}$ using $\mathrm{Cu} \mathrm{K} \alpha$ radiations $(\lambda=0.15418 \mathrm{~nm})$ at scanning rate of $1.00^{\circ}$ per minute in the $2 \theta$ range $10-80^{\circ}$. Raman spectra were recorded using $415 \mathrm{~nm}$ laser. Field

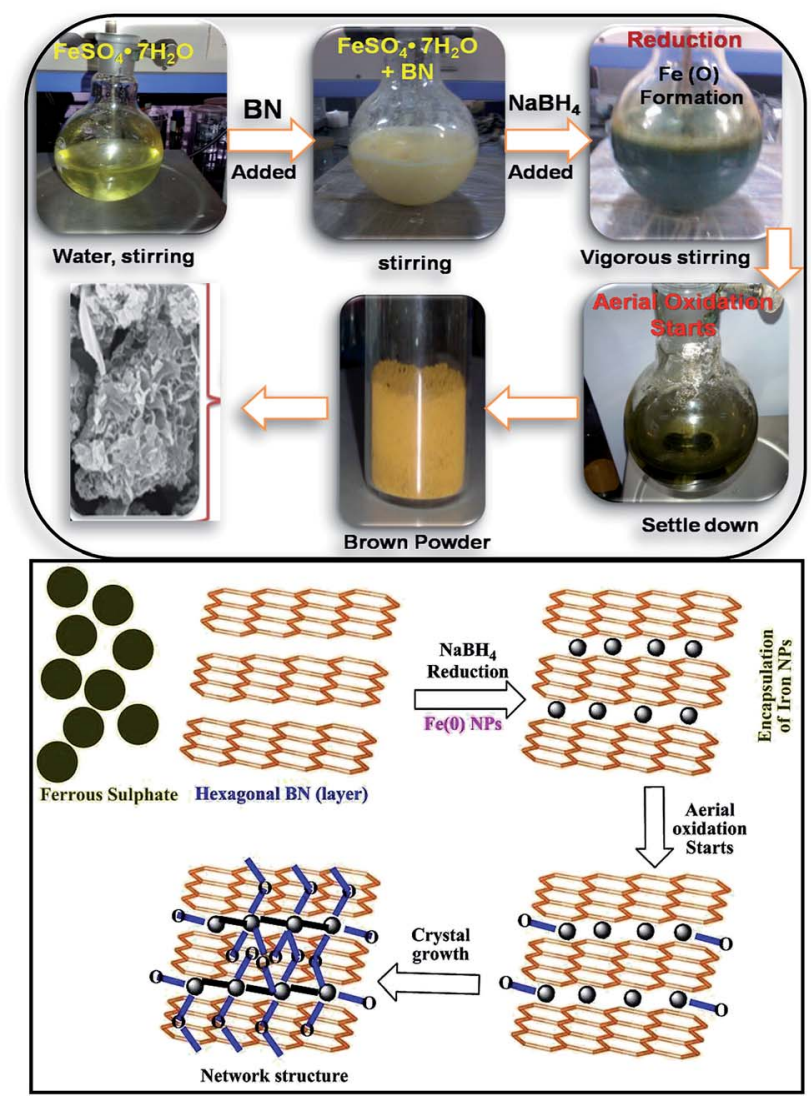

Scheme 1 Proposed strategy for the formation of $\mathrm{BNaFe} \mathrm{O}_{4}$. emission scanning electron microscope (FE-SEM) images were obtained from a Hitachi S-4800 microscope at an operating voltage of $10 \mathrm{kV}$. The sample was coated with platinum for efficient imaging before being charged.

\section{General procedure for multicomponent reaction using $\mathrm{BN} @ \mathrm{Fe}_{3} \mathrm{O}_{4}$}

To malononitrile $(1.1 \mathrm{mmol})$ dissolved in water $(3 \mathrm{ml})$ was added an aldehyde/isatin $(1.0 \mathrm{mmol})$ followed by $\mathrm{BN}_{\mathrm{FFe}} \mathrm{O}_{4}(15 \mathrm{mg})$ and active methylenic diketo compound $(1.0 \mathrm{mmol})$ (dimedone or 4-hydroxy coumarin or cycloalkan-1,3-dione or ethyl acetoacetate/methyl acetoacetate). The reaction mixture was stirred at $80{ }^{\circ} \mathrm{C}$. The progress of the reaction was monitored by TLC and after completion of the reaction the solid precipitate was filtered off and dissolved it again in ethyl acetate. Catalyst was separated with filtration. Product was collected under reduce pressure using ethyl acetate or $\mathrm{CH}_{2} \mathrm{Cl}_{2}$. All the products were characterised using NMR, IR and melting point analysis ESI. $\dagger$

\section{Result and discussion}

\section{Catalyst characterization}

As described in the experimental section, iron oxide was synthesized on BN support by in situ reduction followed by

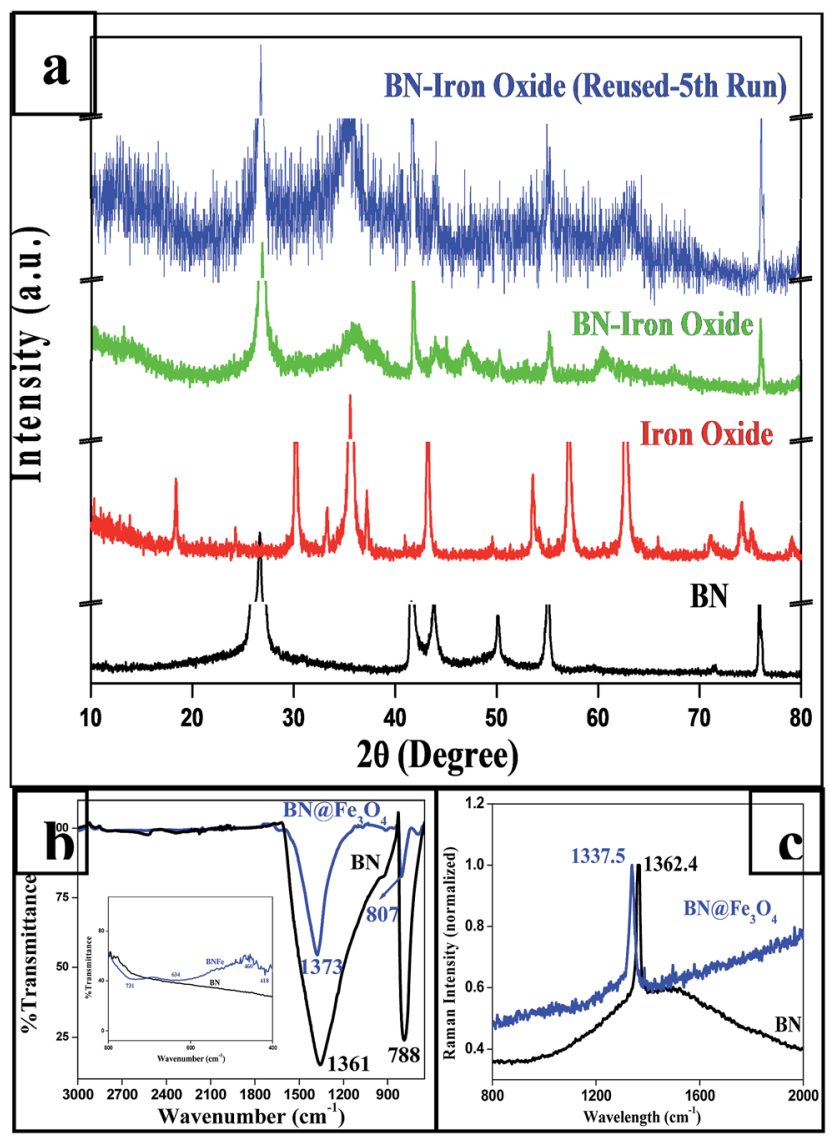

Fig. 2 (a) PXRD of $\mathrm{BN}, \mathrm{BNaFe}_{3} \mathrm{O}_{4}$ and $\mathrm{Fe}_{3} \mathrm{O}_{4}$ and $\mathrm{BNaFe} \mathrm{O}_{4}$ reused (after 5 th cycle); (b) IR spectra of $\mathrm{BN}$ and $\mathrm{BN}\left(\mathrm{Fe}_{3} \mathrm{O}_{4}\right.$; (c) Raman spectra of $\mathrm{BN}$ and $\mathrm{BNaFe} \mathrm{O}_{4}$. 


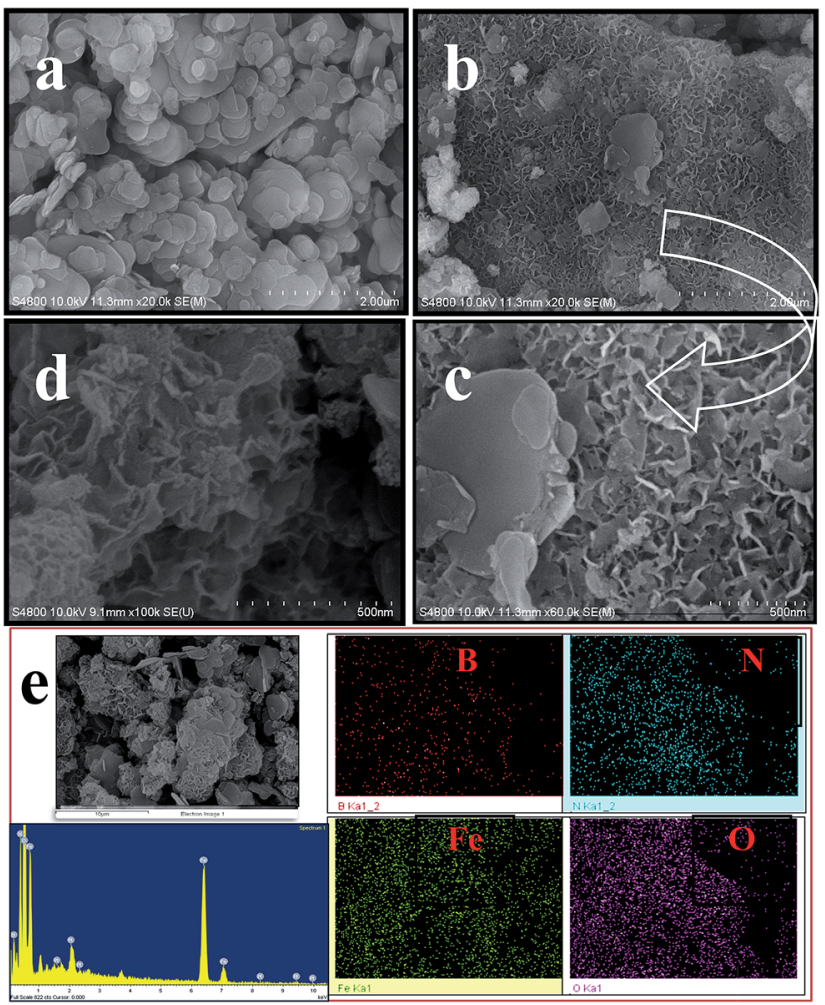

Fig. $3 \mathrm{FE}-\mathrm{SEM}$ image of $\mathrm{BN}(\mathrm{a}), \mathrm{BNaFe}_{3} \mathrm{O}_{4}(\mathrm{~b}$ and $\mathrm{c}$ ), reused $\mathrm{BNaFe} \mathrm{O}_{4}$ (d) at different magnification, EDX line spectra and elemental mapping of $\mathrm{BN}\left(\mathrm{Fe}_{3} \mathrm{O}_{4}(\mathrm{e})\right.$.

aerial oxidation. PXRD patterns of BN and BN-supported iron oxide are shown in Fig. 2a. The diffraction peaks $(2 \theta)$ of hexagonal BN are $26.65^{\circ}(002), 41.53^{\circ}(100), 43.84^{\circ}(101), 50.13^{\circ}$

Table 1 Optimization of reaction conditions for $1 a^{a}$
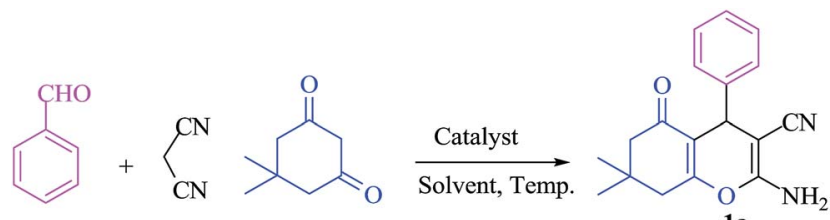

$1 \mathrm{a}$

\begin{tabular}{|c|c|c|c|c|c|}
\hline Run & Catalyst (mol\%) & Solvent & Temp. & Time (min) & Yield $^{b}(\%)$ \\
\hline 01 & - & $\mathrm{H}_{2} \mathrm{O}$ & R.T & 180 & Trace \\
\hline 02 & $\mathrm{BN} @ \mathrm{Fe}_{3} \mathrm{O}_{4}(01 \mathrm{mg})$ & $\mathrm{H}_{2} \mathrm{O}$ & R.T & 180 & 15 \\
\hline 03 & $\mathrm{BN} @ \mathrm{Fe}_{3} \mathrm{O}_{4}(05 \mathrm{mg})$ & $\mathrm{H}_{2} \mathrm{O}$ & R.T & 120 & 25 \\
\hline 04 & $\mathrm{BN} @ \mathrm{Fe}_{3} \mathrm{O}_{4}(10 \mathrm{mg})$ & $\mathrm{H}_{2} \mathrm{O}$ & R.T & 120 & 35 \\
\hline 05 & $\mathrm{BN} @ \mathrm{Fe}_{3} \mathrm{O}_{4}(10 \mathrm{mg})$ & $\mathrm{EtOH}$ & R.T & 120 & 40 \\
\hline 06 & $\mathrm{BN} @ \mathrm{Fe}_{3} \mathrm{O}_{4}(15 \mathrm{mg})$ & $\mathrm{H}_{2} \mathrm{O}$ & R.T & 120 & 60 \\
\hline 07 & $\mathrm{BN} @ \mathrm{Fe}_{3} \mathrm{O}_{4}(15 \mathrm{mg})$ & $\mathrm{H}_{2} \mathrm{O}$ & $60^{\circ} \mathrm{C}$ & 60 & 80 \\
\hline 08 & 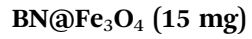 & $\mathrm{H}_{2} \mathrm{O}$ & $80^{\circ} \mathrm{C}$ & 10 & 97 \\
\hline 09 & $\mathrm{BN} @ \mathrm{Fe}_{3} \mathrm{O}_{4}(15 \mathrm{mg})$ & EtOH & Reflux & 10 & 94 \\
\hline 10 & $\mathrm{BN}(15 \mathrm{mg})$ & $\mathrm{H}_{2} \mathrm{O}$ & R.T & 120 & 52 \\
\hline 11 & $\mathrm{BN}(15 \mathrm{mg})$ & $\mathrm{H}_{2} \mathrm{O}$ & $80^{\circ} \mathrm{C}$ & 30 & 68 \\
\hline 12 & $\mathrm{Fe}_{3} \mathrm{O}_{4}(15 \mathrm{mg})$ & $\mathrm{H}_{2} \mathrm{O}$ & $80^{\circ} \mathrm{C}$ & 30 & 65 \\
\hline 13 & $\mathrm{BN} @ \mathrm{Fe}_{3} \mathrm{O}_{4}(20 \mathrm{mg})$ & $\mathrm{H}_{2} \mathrm{O}$ & $80^{\circ} \mathrm{C}$ & 10 & 97 \\
\hline
\end{tabular}

${ }^{a}$ Reaction conditions: benzaldehyde $(1.0 \mathrm{mmol})$, malononitrile (1.1 $\mathrm{mmol})$ and dimedone $(1.0 \mathrm{mmol})$ in $3 \mathrm{ml} \mathrm{solvent.}{ }^{b}$ Isolated yield.
(102), $54.95^{\circ}$ (004) and $75.89^{\circ}$ (110). After the formation iron oxide on BN, additional peaks were observed at 35.95 and 43.93 that confirm the formation of iron oxide. This was also confirmed with the data taken for iron oxide nanoparticles. The reused catalyst also show similar PXRD patterns with the fresh one substantiating that the catalyst does not change after fifth cycles of it use.

Fig. 2b shows the FT-IR spectra of $\mathrm{BN}$ and $\mathrm{BN}_{3} \mathrm{Fe}_{3} \mathrm{O}_{4}$. In the spectrum of BN, strong and board peaks at 1361 and $788 \mathrm{~cm}^{-1}$ were observed due to $\mathrm{B}-\mathrm{N}$ stretching and $\mathrm{B}-\mathrm{N}-\mathrm{B}$ bending vibration respectively. The spectrum of $\mathrm{BN}_{0} \mathrm{Fe}_{3} \mathrm{O}_{4}$ shows additional at 731, 634, 460 and 418 which are attributed to Fe$\mathrm{O}-\mathrm{Fe}$ and $\mathrm{Fe}-\mathrm{O}$ bond vibrations. ${ }^{35}$ The Raman spectra of the same are presented in Fig. 2c. The unique signal at $1362.4 \mathrm{~cm}^{-1}$ is the characteristic of $E_{2 g}$ mode of hexagonal-boron nitride. Peak value shift was observed for both IR (B-N stretching, B-N-B bending vibration) and Raman (signature peak for $\mathrm{E}_{2 \mathrm{~g}}$ mode) in $\mathrm{BN} @ \mathrm{Fe}_{3} \mathrm{O}_{4}$ which might be due to the non-covalent interaction between boron and oxygen. ${ }^{36,37}$

The nitrogen adsorption-desorption isotherm was measured using Smart Instrument, Model No-Smart Prob 92/93 to determine the surface area of the $\mathrm{BN}_{3} @ \mathrm{Fe}_{3} \mathrm{O}_{4}$. Experiment was performed using $\mathrm{N}_{2}(30 \%)$ and $\mathrm{He}(70 \%)$ mixture after the regeneration of the sample. The result shows that, BN have surface area $17.04 \mathrm{~m}^{2} \mathrm{~g}^{-1}$ whereas BN@ $\mathrm{Fe}_{3} \mathrm{O}_{4}$ have surface area $128.62 \mathrm{~m}^{2} \mathrm{~g}^{-1}$. The increase in surface area might be due to the formation of network like structure as observed in FE-SEM image.

The morphologies of $\mathrm{BN}$ and $\mathrm{BN} @ \mathrm{Fe}_{3} \mathrm{O}_{4}$ were studied by FESEM. The FE-SEM image of the samples were taken at different magnification are shown in Fig. 3. Spherical platelets like

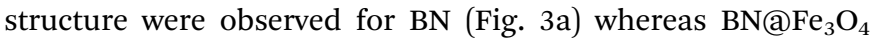
showed network like structures (Fig. $3 \mathrm{~b}-\mathrm{c}$ ). The formation of network structure is proposed in Scheme 1. It is believed that network structure forms as a result of two-stage growth process, which involves a fast nucleation of amorphous primary particles followed by a slow aggregation and crystallization of primary particles. In our experiment, $\mathrm{Fe}(0)$ is the primary particles that undergo secondary growth with the formation of network structure. Several factors, including crystal-face attraction, electrostatic and dipolar fields associated with the aggregate, hydrophilic interactions, hydrogen bonds and van der Waals forces may have effects on the self-assembly to form final structure. ${ }^{2,10,12,17,18}$ The reused catalyst has similar morphology as the fresh one indicating that there is relatively no change in structure after fifth cycles of it use (Fig. 3d).

The composition of $\mathrm{BN} @ \mathrm{Fe}_{3} \mathrm{O}_{4}$ was confirmed from EnergyDispersive X-ray spectroscopy (EDX) analysis and the line spectrum is shown in Fig. 3e. To further study the spatial homogeny of the elemental distribution of $\mathrm{BN} @ \mathrm{Fe}_{3} \mathrm{O}_{4}, \mathrm{EDX}$ elemental mapping was taken. It indicates the homogeneous distribution of $\mathrm{B}, \mathrm{N}, \mathrm{Fe}$ and $\mathrm{O}$ elements throughout the sample.

\section{Optimization of catalyst loading}

For this study, we optimized reaction condition taking benzaldehyde $(1.0 \mathrm{mmol})$, malononitrile $(1.1 \mathrm{mmol})$ and dimedone $(1.0 \mathrm{mmol})$ as model substrate. The domino effect of catalyst, 
Table 2 BN@Fe ${ }_{3} \mathrm{O}_{4}$ catalyzed synthesis of pyran derivatives with aldehydes, malononitrile and cycloalkane-1,3-dione (1a-i) ${ }^{a}$ or 1,3 -diketoesters $(2 a-f)^{a}$ or 4-hydroxycoumarine $(3 a-e)^{a}$

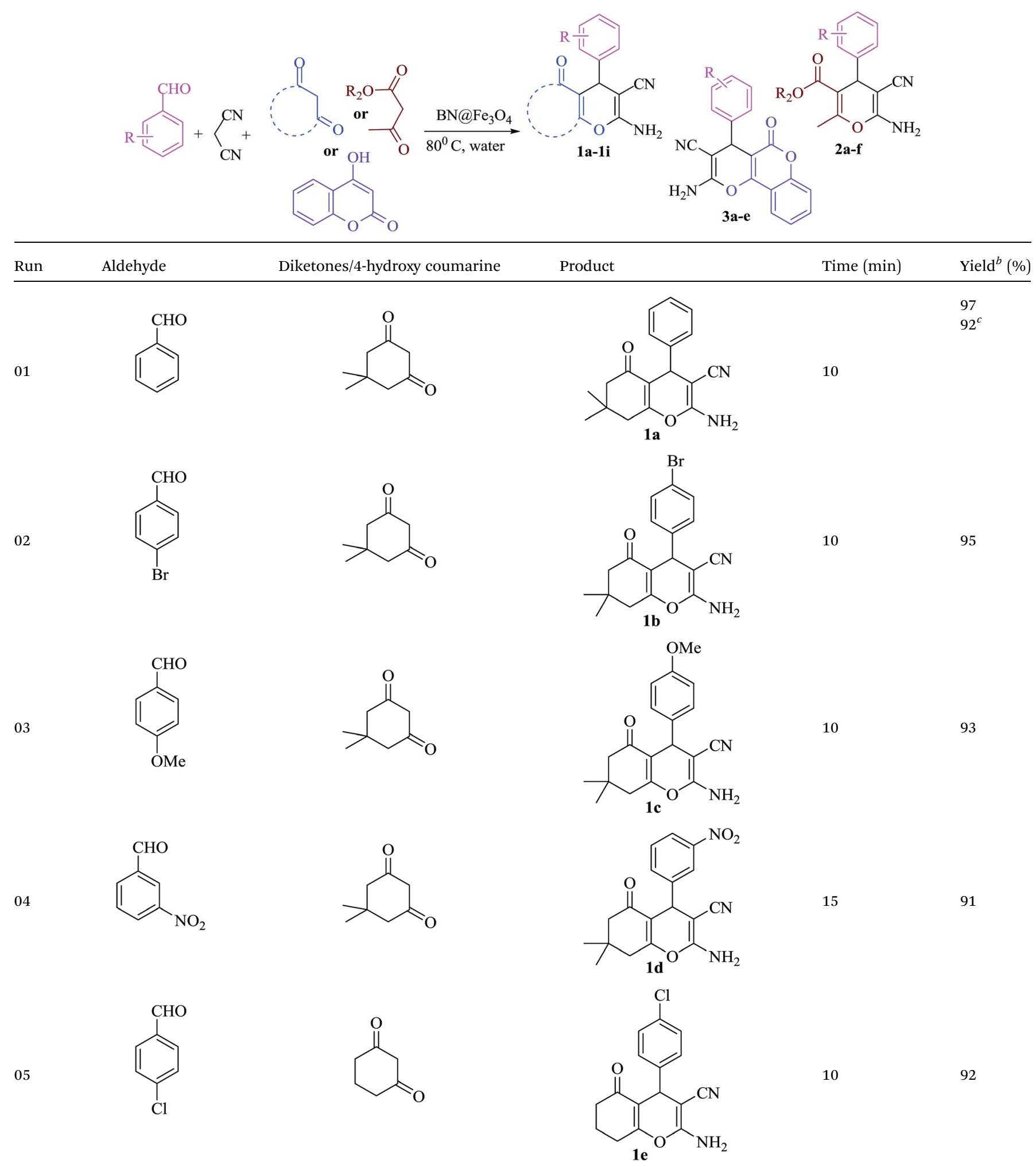


Table 2 (Contd.)

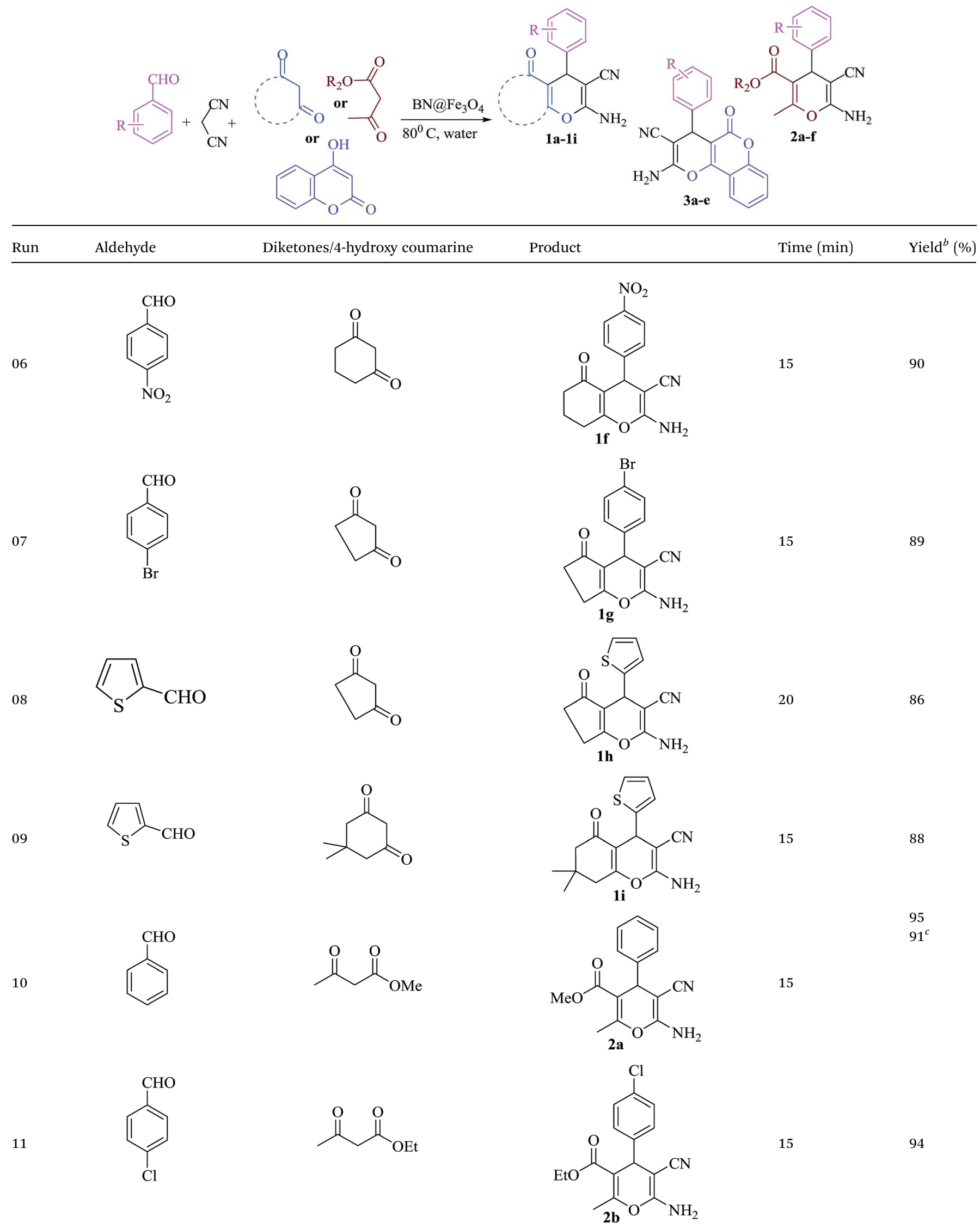


Table 2 (Contd.)

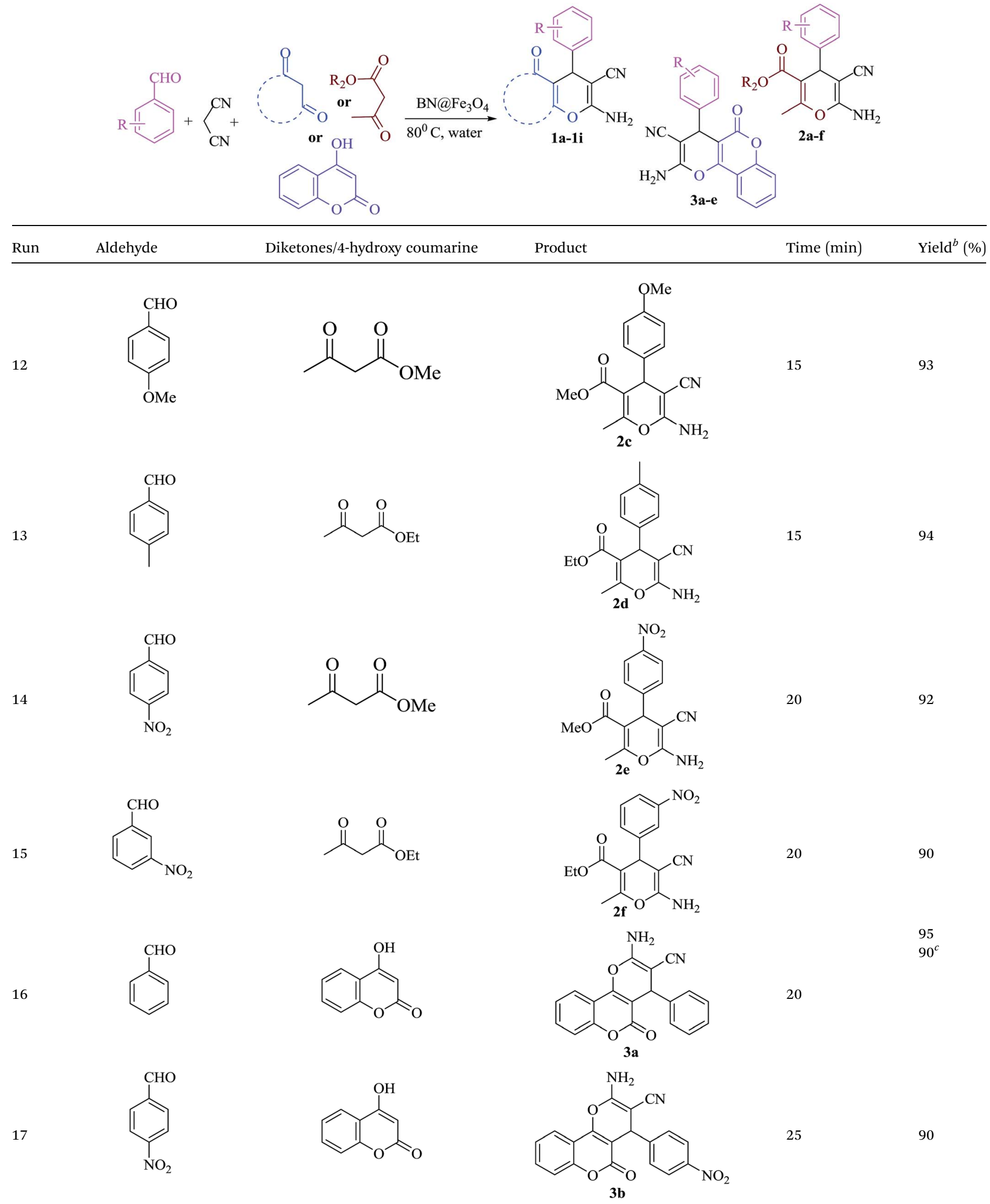




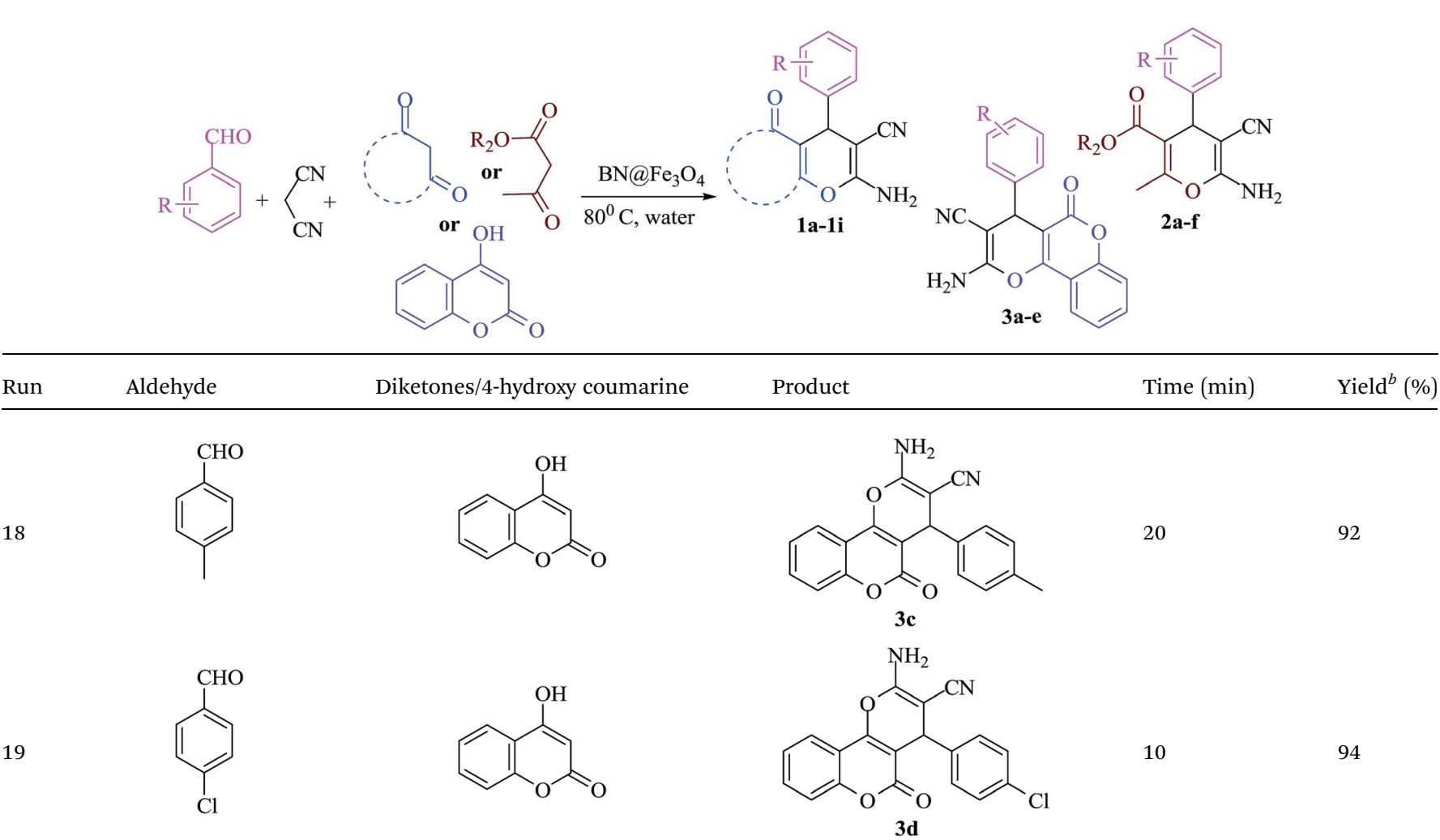

\footnotetext{
${ }^{a}$ Reaction conditions: aldehyde $(1.0 \mathrm{mmol})$, malononitrile $(1.1 \mathrm{mmol})$ and cyclic diketones/1,3-diketoesters $(1.0 \mathrm{mmol})$ or 4 -hydroxycoumarine in 3 $\mathrm{ml}$ water at $80{ }^{\circ} \mathrm{C} .{ }^{b}$ Isolated yield. ${ }^{c}$ Yield after 5 th cycle.
}

solvent and temperature are summarized in Table 1. It was observed that trace amount of product was obtained in 3 hours without any catalyst in water at room temperature (Table 1 , run 1). We initially tried reaction with $1 \mathrm{mg}$ of catalyst ( $\left.\mathrm{BN} @ \mathrm{Fe}_{3} \mathrm{O}_{4}\right)$ under the same condition as above and $15 \%$ of the product was obtained in 3 hours (Table 1, run 2). Increase in yield of the product was observed when the catalyst loading was increased to $5 \mathrm{mg}$ or $10 \mathrm{mg}$ using water (Table 1, run 3-4) or EtOH (Table 1, run 5) as solvent. When the reaction was carried out with $15 \mathrm{mg}$ of catalyst at $60{ }^{\circ} \mathrm{C}, 80 \%$ of product (Table 1 , run 7 ) was obtained whereas at room temperature only $60 \%$ of product (Table 1 , run 6) was observed. On increasing the temperature of reaction to 80 ${ }^{\circ} \mathrm{C}$, the reaction yield increases to $97 \%$ (Table 1 , run 8 ). $94 \%$ of product was obtained (Table 1, run 9) with $15 \mathrm{mg}$ of catalyst in EtOH under reflux condition. When the reaction was performed with $15 \mathrm{mg}$ BN at room temperature and $80{ }^{\circ} \mathrm{C}, 52 \%$ and $68 \%$ product were obtained respectively (Table 1 , run 10-11). $\mathrm{Fe}_{3} \mathrm{O}_{4}$ nanoparticles produced $65 \%$ of the product (Table 1,12 ). We further increase the catalyst loading to $20 \mathrm{mg}$ to check efficacy (Table 1, run 13) but the best result was obtained with $15 \mathrm{mg}$ of catalyst on water at $80^{\circ} \mathrm{C}$. Accordingly, all the reactions discussed herein were conducted with this combination unless stated otherwise.

The reaction of various aromatic aldehydes having substituent such as $\mathrm{Br}$, OMe and $\mathrm{NO}_{2}$ were examined with malononitrile and dimedone under the optimized reaction conditions and the results are presented in Table 2 (run 1-4). In addition, the reaction of 1,3-cyclohexanedione or 1,3cyclopentanedione was also carried out under similar reaction conditions with substituted aldehyde and malononitrile and 89-92\% yield was obtained (Table 2, run 5-7). The heterocyclic aryl aldehyde also produced the corresponding product in good yields with same alacrity (Table 2, run 8 and 9). The scope of this methodology was also investigated with 1,3-diketoesters using aldehyde and malononitrile. It is important to note that the reaction occurred at room temperature in $\mathbf{1 5}$ minutes. It is evident from Table 2 that nitro substituted aldehyde took little longer reaction time and give comparatively lower yield (run 14 and 15).

To demonstrate the scope, the reactions of various aromatic aldehydes were examined with malononitrile and 4-hydroxycoumarin under identical reaction conditions and the results are in Table 2 (run 16-19). Heterocyclic aldehyde also furnish product in good yield (Table 2, run 20).

Under similar experimental conditions, we further use isatin or substituted isatin $(\mathrm{Cl}$ and $\mathrm{Br})$ instead of aldehyde with malononitrile and dimedone or cyclohexane-1,3-dione or cyclopentane-1,3-dione to check the efficacy of catalyst. The reaction proceeds well and the products were isolated in good yields (Table 3). The scope of this procedure was further extended 
Table $3 \mathrm{BNaFe}_{3} \mathrm{O}_{4}$ catalyzed synthesis of highly functionalized spirooxindole with isatin, malononitrile and cycloalkane-1,3-dione (4a-e) ${ }^{a}$ or 1,3-diketoesters $(5 \mathrm{a}-\mathrm{d})^{a}$

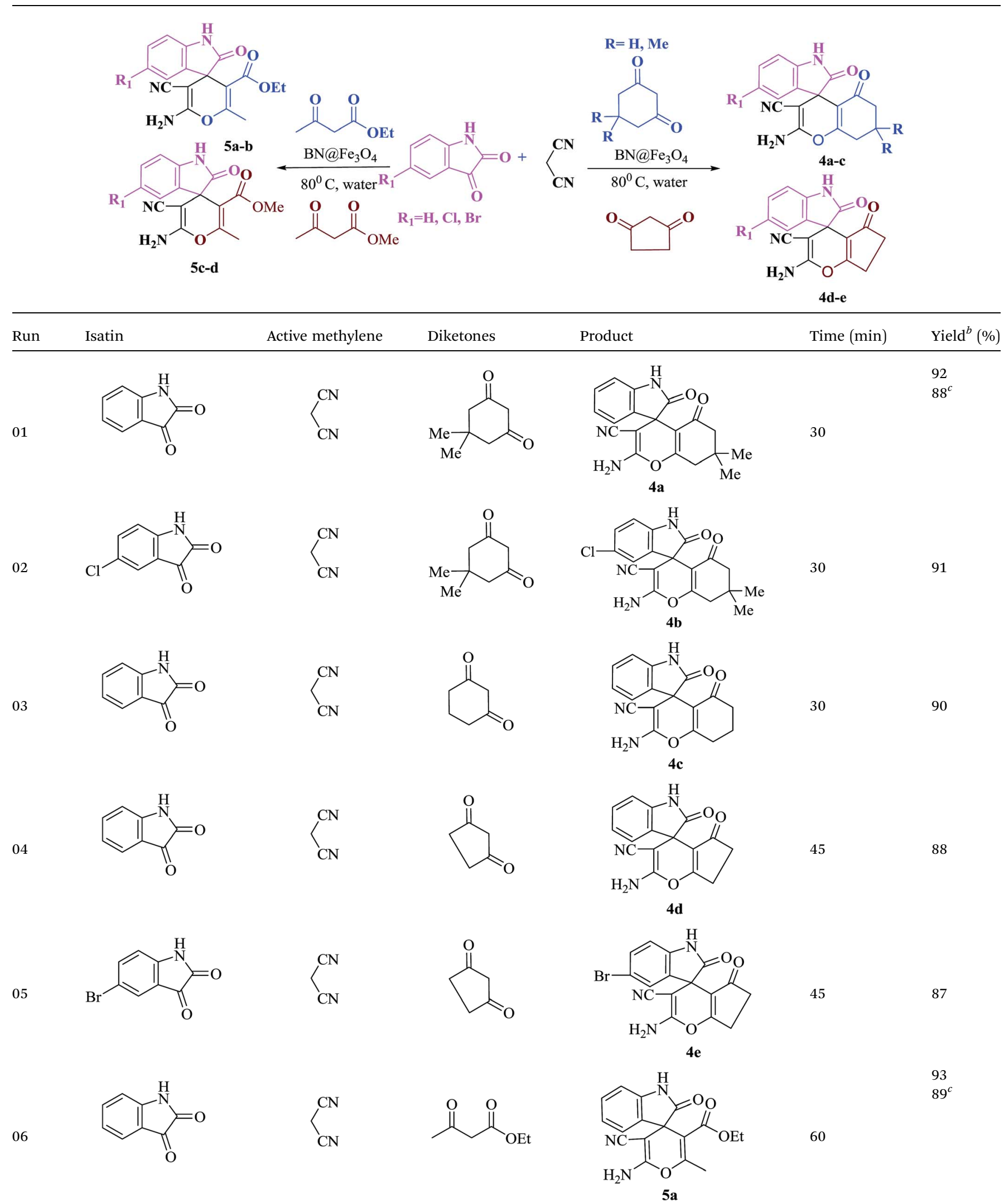




a

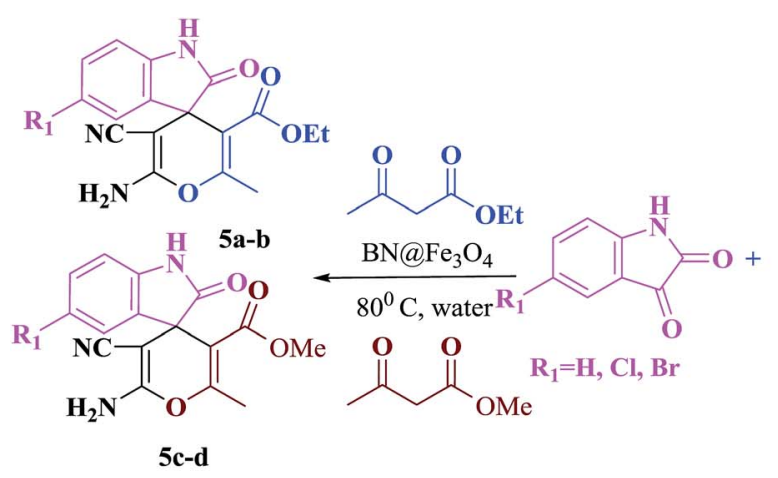<smiles>[R]C1CC(=O)CC(=O)C1[PH](=O)[O-]</smiles>

07<smiles>O=C1Nc2ccc(Cl)cc2C1=O</smiles><smiles>N#CCC#N</smiles><smiles>CCOC(=O)CC(C)=O</smiles><smiles>CCOC(=O)C1=C(C)OC(N)=C(C#N)C12C(=O)Nc1ccc(Cl)cc12</smiles><smiles>O=C1Nc2ccc(Br)cc2C1=O</smiles><smiles>N#CCC#N</smiles><smiles>COC(=O)CC(C)=O</smiles>

09<smiles>O=C1Nc2ccc(Cl)cc2C1=O</smiles><smiles>N#CCC#N</smiles><smiles>COC(=O)CC(C)=O</smiles><smiles>COC(=O)C1=C(C)OC(N)=C(C#N)C12C(=O)Nc1ccc(Br)cc12</smiles>

90<smiles>COC(=O)C1=C(C)OC(N)=C(C#N)C12C(=O)Nc1ccc(Cl)cc12</smiles>

Yield $^{b}(\%)$ 
Table 4 BNaFe ${ }_{3} \mathrm{O}_{4}$ catalyzed synthesis of highly functionalized spirooxindole with isatin, malononitrile and 4-hydroxy-derivatives or barbituric acid or 2-thiobarbituric $(6 \mathrm{a}-\mathrm{g})^{a}$<smiles>[R]c1ccc2c(c1)C1(C(=O)N2)C(C(N)=O)=C(N)OC2=C1C(=O)NC([Y])NC2=O</smiles>

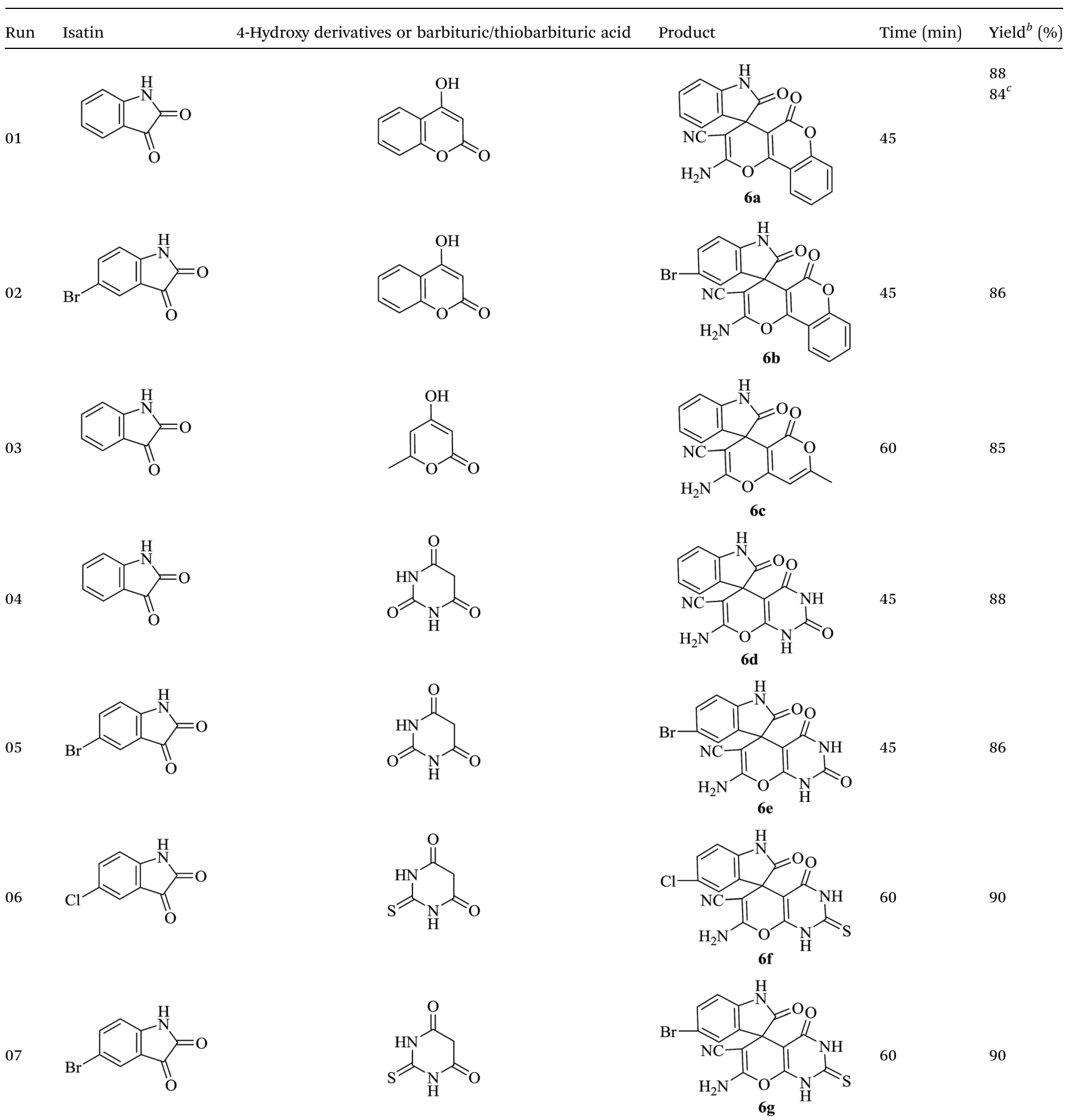




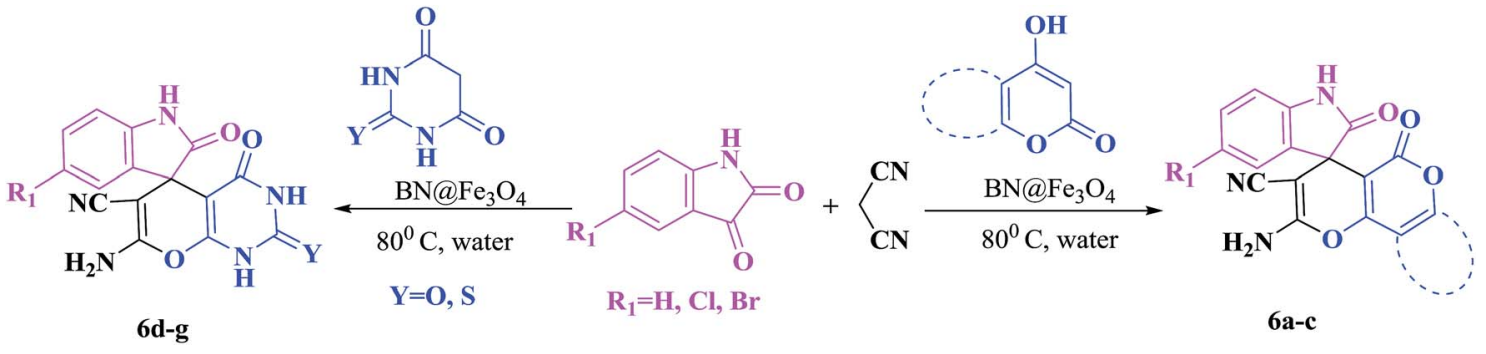

\begin{tabular}{|c|c|c|c|c|c|}
\hline Run & Isatin & 4-Hydroxy derivatives or barbituric/thiobarbituric acid & Product & Time (min) & Yield $^{b}(\%)$ \\
\hline
\end{tabular}
${ }^{a}$ Reaction conditions: isatin derivatives $(1.0 \mathrm{mmol})$, malononitrile $(1.1 \mathrm{mmol})$ and 4 -hydroxy derivatives or barbituric acid/thiobarbituric acid (1.0
mmol) in $3 \mathrm{ml}$ water under $80^{\circ} \mathrm{C} .{ }^{b}$ Isolated yield. ${ }^{c}$ Yield after 5 th cycle.

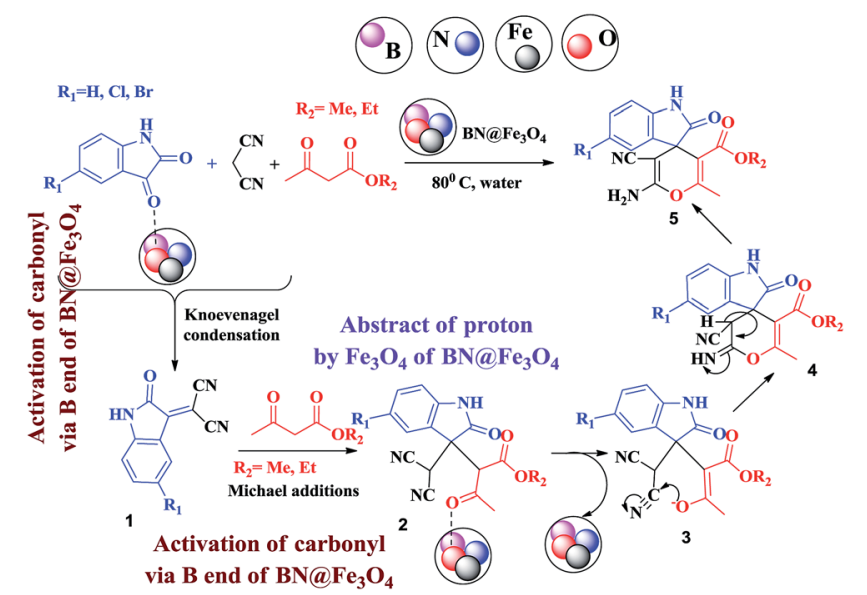

Scheme 2 Proposed mechanism for the synthesis of highly functionalised spirooxindole derivatives.

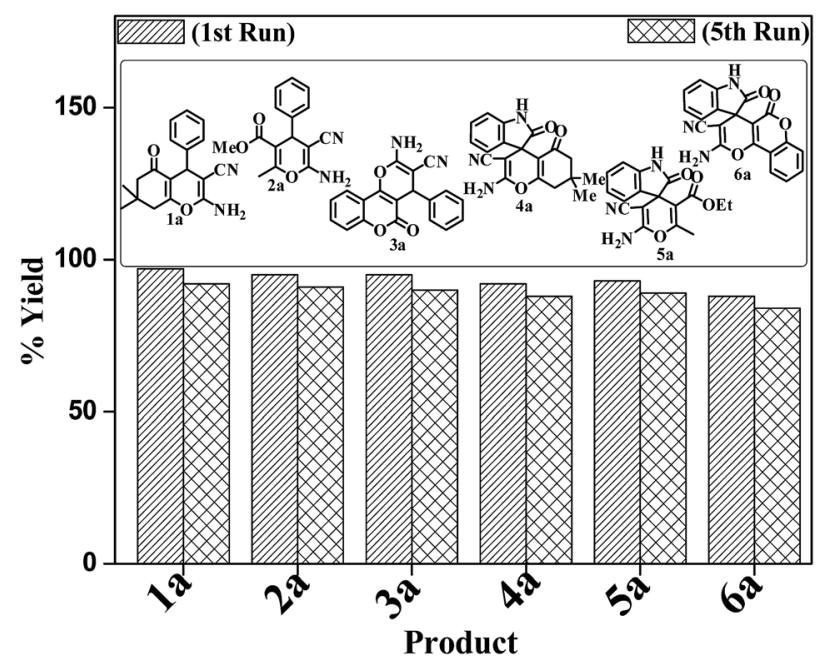

Fig. 4 Reusability of $\mathrm{BNaFe} \mathrm{O}_{4}$ with different substrates $1 \mathrm{a}, 2 \mathrm{a}, 3 \mathrm{a}, 4 \mathrm{a}$, $5 a$ and $6 a$.
Table 5 Comparison of synthesis of pyran derivatives with reported protocols for compound 1a

\begin{tabular}{llll}
\hline Sl no. & Catalyst (ref. 33) & $\begin{array}{l}\text { Reaction conditions } \\
\text { (temp./solvent/time) }\end{array}$ & Yield \\
\hline 1 & $\mathrm{Ni}\left(\mathrm{NO}_{3}\right)_{2} \cdot 6 \mathrm{H}_{2} \mathrm{O}$ & Refluxing $/ \mathrm{H}_{2} \mathrm{O} / 20 \mathrm{~min}$ & 88 \\
2 & $\mathrm{Pd} \mathrm{nanoparticles}$ & Refluxing $/ \mathrm{CH}_{3} \mathrm{CN} / 4.2 \mathrm{~h}$ & 88 \\
3 & $\mathrm{PPA}-\mathrm{SiO}_{2}$ & Refluxing $/ \mathrm{H}_{2} \mathrm{O} / 10 \mathrm{~min}$ & 93 \\
4 & $\mathrm{Amberlyst} \mathrm{A21}$ & $\mathrm{RT} / \mathrm{EtOH} / 1 \mathrm{~h}$ & 84 \\
5 & $\mathrm{SB}-\mathrm{DABCO}$ & $\mathrm{RT} / \mathrm{EtOH} / 25 \mathrm{~min}$ & 95 \\
6 & $\mathrm{DMAP}$ & Refluxing $/ \mathrm{EtOH} / 15 \mathrm{~min}$ & 94 \\
7 & $\mathrm{MgO}$ & $\mathrm{RT} / \mathrm{neat} / 25 \mathrm{~min}$ & 86 \\
8 & $\mathrm{~N}-\mathrm{Methylimidazole}$ & $\mathrm{RT} / \mathrm{H}_{2} \mathrm{O} / 90 \mathrm{~min}$ & 90 \\
9 & $\mathrm{BN@Fe} \mathrm{O}_{4}$ & Refluxing $/ \mathrm{H}_{2} \mathrm{O} / 10 \mathrm{~min}$ & 97
\end{tabular}

are charted in Table 5. It is clear from the table that the present protocol is better than the reported protocols with respect to time, solvent and yields.

In conclusion, a new catalyst $\mathrm{BN} @ \mathrm{Fe}_{3} \mathrm{O}_{4}$ has been developed and characterized by powder XRD, FT-IR, Raman, BET and FESEM. It efficiently catalyzes the formation of highly functionalized pyrans and spirooxindoles derivatives of potential synthetic and pharmacological interest in domino fashion. This protocol offers diverse advantages such as the high yields of product without any column chromatography, simple work-up and use of inexpensive and recyclable catalyst. It is also capable of working efficiently on water thereby satisfying some principle of "Green Chemistry".

\section{Acknowledgements}

A. $\mathrm{M}$ is thankful to IIT Patna for his research fellowship. Authors are thankful to SAIF (Panjab University, Chandigarh) and IIT Kanpur and IISER Kolkata for NMR facility.

\section{References}

1 A. Corma, H. Garcia and F. X. Llabrés i Xamena, Chem. Rev., 2010, 110, 4606-4655. 
2 M. B. Gawande, P. S. Branco and R. S. Varma, Chem. Soc. Rev., 2013, 42, 3371-3393.

3 C. N. R. Rao, A. Müller and A. K. Cheetham, The Chemistry of nanomaterials, Wiley-VCH Verlag GmbH \& Co. KGaA, 2005, pp. 1-11.

4 G. Schmid, Chem. Rev., 1992, 92, 1709-1727.

5 N. T. S. Phan, C. S. Gill, J. V. Nguyen, Z. J. Zhang and

C. W. Jones, Angew. Chem., Int. Ed., 2006, 45, 2209-2212.

6 I. Bauer and H.-J. Knölker, Chem. Rev., 2015, 115, 3170-3387.

7 A. Primo, S. Navalón, A. M. Asiri and H. García, Chem.-Eur. J., 2015, 21, 324-330.

8 L. Wang, C. Sun, L. Xu and Y. Qian, Catal. Sci. Technol., 2011, 1, 1119-1123.

9 A. Molla and S. Hussain, Curr. Catal., 2013, 2, 88-95.

10 A. Nag, K. Raidongia, K. P. S. S. Hembram, R. Datta, U. V. Waghmare and C. N. R. Rao, ACS Nano, 2010, 4, 1539-1544.

11 S. Rostamizadeh, N. Shadjou, M. Azad and N. Jalali, Catal. Commun., 2012, 26, 218-224.

12 D. Wang and D. Astruc, Chem. Rev., 2014, 114, 6949-6985.

13 R. B. N. Baig, M. N. Nadagouda and R. S. Varma, Coord. Chem. Rev., 2015, 287, 137-156.

14 R. Hudson, Y. Feng, R. S. Varma and A. Moores, Green Chem., 2014, 16, 4493-4505.

15 V. Polshettiwar, R. Luque, A. Fihri, H. Zhu, M. Bouhrara and J.-M. Basset, Chem. Rev., 2011, 111, 3036-3075.

16 J. Hua and Y. HeQing, Sci. China, Ser. E: Technol. Sci., 2008, 51, 1911-1920.

17 N. Islam, L. V. Phong, J. R. Jeong and C. G. Kim, Thin Solid Films, 2011, 519, 8277-8279.

18 Y. Deng, L. Wang, W. Yang and S. Fu, J. Magn. Magn. Mater., 2003, 257, 69-78.

19 S. Franger, P. Berthet and J. Berthon, J. Solid State Electrochem., 2004, 8, 218-223.

20 W. Wu, Q. He and C. Jiang, Nanoscale Res. Lett., 2008, 3, 397-415.

21 R. Y. Honga, T. T. Pan and H. Z. Li, J. Magn. Magn. Mater., 2006, 303, 60-68.

22 H. Hu, H. Yang, P. Huang, D. Cui, Y. Peng, J. Zhang, F. Lu, J. Lian and D. Shi, Chem. Commun., 2010, 46, 3866-3868.

23 C. Li, Y. Wei, A. Liivat, Y. Zhu and J. Zhu, Mater. Lett., 2013, 107, 23-26.

24 L. F. Tietze, G. Brasche and K. Gericke, Domino reactions in organic synthesis, Wiley-VCH, Weinheim, 1996.

25 B. Ganem, Acc. Chem. Res., 2009, 42, 463-472.

26 M. M. C. Lo, C. S. Newmann, S. Nagayams, E. O. Perlstein and S. L. Schreiber, J. Am. Chem. Soc., 2005, 127, 10130-10131.

27 M. M. G. Kumari, Eur. J. Med. Chem., 2011, 46, 1181-1188.

28 B. K. S. Yeung, B. Zou, M. Rottmann, S. B. Lakshminarayana, S. H. Ang, S. Y. Leong, J. Tan, J. Wong, S. Keller-Maerki, C. Fischli, A. Goh, E. K. Schmitt, P. Krastel, E. Francotte, K. Kuhen, D. Plouffe, K. Henson, T. Wagner, E. A. Winzeler, F. Petersen, R. Brun, V. Dartois, T. T. Diagana and T. H. Keller, J. Med. Chem., 2010, 53, 5155-5164.

29 V. V. Vintonyak, K. Warburg, H. Kruse, S. Grimme, K. Hübel, D. Rauh and H. Waldmann, Angew. Chem., Int. Ed., 2010, 49, 5902-5905.
30 P. K. Paliwal, S. R. Jetti and S. Jain, Med. Chem. Res., 2013, 22, 2984-2990.

31 A.-G. E. Amr, A. M. Mohamed, S. F. Mohamed, N. A. AbdelHafez and A. E.-F. G. Hammam, Bioorg. Med. Chem., 2006, 14, 5481-5488.

32 D. Kumar, V. B. Reddy, S. Sharad, U. Dube and S. A. Kapur, Eur. J. Med. Chem., 2009, 44, 3805-3809.

33 (a) B. Boumoud, A. A. Yahiaoui, T. Boumoud and A. Debache, J. Chem. Pharm. Res., 2012, 4, 795-799; (b) M. Saha and A. K. Pal, Adv. Nanopart., 2012, 1, 61-70; (c) A. Davoodnia, S. Allameh, S. Fazli and N. T. Hoseini, Chem. Pap., 2011, 65, 714-720; (d) M. Bihani, P. P. Bora, G. Bez and H. Askari, C. R. Chim., 2013, 16, 419-426; (e) A. Hasaninejad, M. Shekouhy, N. Golzar, A. Zare and M. M. Doroodmand, Appl. Catal., A, 2011, 402, 11-22; (f) A. T. Khan, M. Lal, S. Ali and M. M. Khan, Tetrahedron Lett., 2011, 52, 5327-5332; $(g)$ D. Kumar, V. B. Reddy, S. Sharad, U. Dube and S. Kapur, Eur. J. Med. Chem., 2009, 44, 3805-3809; (h) X. Z. Lian, Y. Huang, Y. Q. Li and W. J. Zheng, Monatsh. Chem., 2008, 139, 129-131.

34 (a) H. Hagiwara, A. Numamae, K. Isobe, T. Hoshi and T. Suzuki, Heterocycles, 2006, 68, 889-895; (b) S. B. Bandgar, B. P. Bandgar, B. L. Korbad, J. V. Totre and S. Patil, Aust. J. Chem., 2007, 60, 305-307; (c) M. A. Zolfigol, A. Khazaei, A. R. Moosavi-Zare, J. Afsar, V. Khakyzadeh and O. Khaledian, J. Chin. Chem. Soc., 2015, 62, 398-403; (d) G. M. Ziarani, A. Badiei, S. Mousavi, N. Lashgari and A. Shahbazi, Chin. J. Catal., 2012, 33, 1832-1839; (e) M. Hosseini-Sarvari and M. Tavakolian, Comb. Chem. High Throughput Screening, 2012, 15, 826-834; $(f)$ M. A. Nasseri, F. Kamali and B. Zakerinasab, RSC Adv., 2015, 5, 2651726520; $(g)$ N. Lashgari, G. M. Ziarani, A. Badiei and M. Zarezadeh-Mehrizib, J. Heterocycl. Chem., 2014, 51, 1628-1633; (h) H. R. Safaei, M. Shekouhy, S. Rahmanpur and A. Shirinfeshan, Green Chem., 2012, 14, 1696-1704; (i) R. Y. Guo, Z. M. An, L. P. Mo, R. Z. Wang, H. X. Liu, S. X. Wang and Z. H. Zhang, ACS Comb. Sci., 2013, 15, 557563; (j) A. Khalafi-Nezhad, E. S. Shahidzadeh, S. Sarikhani and F. Panahi, J. Mol. Catal. A: Chem., 2013, 379, 1-8; (k) R. Sridhar, B. Srinivas, B. Madhav, V. P. Reddy, Y. V. D. Nageswar and K. R. Rao, Can. J. Chem., 2009, 87, 1704-1707; (l) G. M. Ziarani, S. Faramarzi, N. Lashgari and A. Badiei, J. Iran. Chem. Soc., 2014, 11, 701-709; (m) A. Rostami, B. Atashkar and H. Gholami, Catal. Commun., 2013, 37, 69-74; (n) A. Saha, S. Payra and S. Banerjee, RSC Adv., 2015, 5, 101664-101671; (o) Y. Li, H. Chen, C. Shi, D. Shi and S. Ji, J. Comb. Chem., 2010, 12, 231-237.

35 C. Y. Zhi, Y. Bando, C. C. Tang and D. Golberg, Appl. Phys. Lett., 2005, 86, 213110-213113.

36 R. Geick, C. H. Perry and G. Rupprecht, Phys. Rev., 1966, 146, 543-547.

37 S. Reich, A. C. Ferrari, R. Arenal, A. Loiseau, I. Bello and J. R. Roberton, Phys. Rev. B: Condens. Matter Mater. Phys., 2005, 71, 205201-205212. 